\title{
Psychological Well-Being and Its Relationship with Active and Passive Procrastination: A Study on Students of a Business University in Karachi
}

\author{
Dr. Zeenat Ismail \\ Professor - Department of Social Sciences \& Liberal Arts, Institute of Business Administration - Karachi \\ Email: zismail@iba.edu.pk
} Doi:10.5901/ajis.2016.v5n3p87

\section{Abstract}

\begin{abstract}
Procrastination has been seen as a dysfunctional and an unproductive behavior, which impacts the psychological well-being negatively. However, a study by Chu and Choi (2005) gave a different perspective to procrastination by dividing it into active and passive (traditional) procrastination. This present study examines how psychological well-being is related to the two dimensions of procrastination, since different forms might have different effects on psychological well-being. It was hypothesized that high psychological well-being will be positively correlated with active procrastination and low psychological well-being will be negatively correlated with passive procrastination. For the research, 120 participants form Institute of Business Administration (IBA), Karachi were selected, between the ages of 18 to 24. Morgan and Choi's Active Procrastination Scale, Chu and Choi's Passive Procrastination Scale, and Ryff's Scales of Psychological Well-Being were used. Multiple linear regression analysis was used to find out the influences of active and passive procrastination on psychological wellbeing. The two predictors account for $88 \%$ of the variance in psychological wellbeing, $F(2,117)=5.679, p<0.05, R 2=.0 .88$. The relationship between active procrastination and psychological wellbeing and passive procrastination and psychological wellbeing was investigated using Pearson correlation coefficient. The results showed that there is a small positive correlation between the active procrastination and psychological wellbeing $(r=0.243, N=120, p<0.05)$ and a small negative correlation between the two $(r=-0.023, N=120, p<0.05)$. Independent $T$-test was used to determine the link between psychological wellbeing, active procrastination, passive procrastination and gender. For Active Procrastination there was no significant difference in the scores of males and females as the magnitude of the differences in the means was very small (eta squared=0.00038); for Passive Procrastination there was no significant difference in the scores of males and females as the magnitude of the differences in the means was very small (eta squared=0.0011); and for Psychological Wellbeing there was no significant difference in the scores of males and females as the magnitude of the differences in the means was very small (eta squared $=0.0585$ ).
\end{abstract}

Keywords: Procrastination, Active Procrastination, Passive Procrastination, Psychological Well-being 1

\section{Introduction}

Procrastination according to the Oxford Dictionary, "the lack or absence of self-regulated performance and the behavioral tendency to postpone what is necessary to reach a goal." It is also known as the thief of time. It is a well-known phenomenon and effects more or less every individual at some point in their life. Various researchers have offered numerous definitions of procrastination. Ellis and Knaus (1997) defined procrastination as "the lack or absence of selfregulated performance and the behavioral tendency to postpone what is necessary to reach a goal." Harris and Sutton (1983) have defined it as "an act of putting off a task that either the focal person or other role senders expect to be done at the present time". Solomon and Rothblum (1984) have described procrastination as "the act of needlessly delaying tasks to the point of experiencing subjective discomfort". Lay (1986) considers procrastination as "the tendency to delay

\footnotetext{
${ }_{1}^{1}$ Psychological Well-Being: According to Ryff (1989), there are three interrelated components to psychological well-being: life satisfaction, unpleasant affect, and pleasant affect. Life satisfaction means a mental sense of satisfaction with life itself and affect refers to pleasant or unpleasant moods and feelings (Ryff, 1989).

Procrastination: According to the Oxford Dictionary, "the lack or absence of self-regulated performance and the behavioral tendency to postpone what is necessary to reach a goal."

Active Procrastination: Active procrastination is when the procrastinators are motivated to work hard when confronted with last minute deadlines; they delay the tasks intentionally but are still able to meet the deadlines because of their motivation (Morgan \& Choi, 2009).

Passive Procrastination: Passive procrastination is when someone does not intend to procrastinate but they do so due to their inability to make quick and effective decisions or when they are under pressure of the upcoming task (Choi \& Chu, 2005).
} 
that which is necessary to reach some goal".

The phenomenon of procrastination has been studied widely by many social scientists. Procrastination cannot be confined to any particular stage of human growth. Delving into these the work of previous researchers, it is evident that university students are more particularly known to be adept at procrastinating, subsequently they are the ones more affected by procrastinating behavior (Brownlow \& Reasinger, 2000; Zarick \& Stonebraker, 2011; Ellis \& Knaus, 1977). In a study by Schourwenburg, Lay, Pychyl \& Ferrari (2004), $70 \%$ of the students are reported to have procrastinating behavior in North America. The study by Goode (2008) confirms this finding as $20 \%$ of the general population and $70 \%$ of the college students appeared having procrastinating tendency in their routine. According to Yaakub (2000) procrastination and increase in age have a closer relationship; the younger students tend to procrastinate more whereas the older women have more anxiety problems developing which lead to anxiety and low self-esteem in high school students (Owens \& Newbegin, 1997). Students attempt to come up with nuanced excuses to delay their academic work and evade academic responsibilities. Procrastination involves time management and affective, cognitive, and behavioral components (Fee \& Tangney, 2000).

Although there is a severe dearth of research on procrastination in Pakistan, there have emerged several notable studies on the topic of procrastination. The study by Hussain and Sultan (2010) focused on analyzing the factors of procrastination and its effects on students. The results indicated that students who procrastinate are unable to manage their studies effectively. As a result, they resort to short cuts and unfair means to overcome their academic paucities. They are unable to obtain high academic achievements which leads to a development of hostile, irritable and aggressive temperament towards themselves and the people around them. They may also get demotivated, which can cause them to develop the habits of drinking, smoking and taking sleeping pills at nights which make them passive leading to creating anxiety, depression having a negative impact on their studies. However, the study by Saleem and Rafique (2012) found that students with high self-esteem procrastinate less where as those who procrastinate more have comparatively lower self-esteem. Furthermore, the study pointed that procrastination and self-esteem remain same and is not difference across birth order, meaning that first born, middle born, last born and only child do not differ with regard to self-esteem and procrastination.

Since long, procrastination has been regarded as an unfruitful, unproductive attitude characteristic of dysfunctional behavior, and has been viewed only in a single dimension. The study by Chu and Choi (2005) reveals the bidimensionality of procrastination by looking at two different natures of procrastination - active and passive. Active procrastination is when the procrastinators are motivated to work hard when confronted with last minute deadlines; they delay the tasks intentionally but are still able to meet the deadlines because of their motivation (Morgan \& Choi, 2009) and Passive procrastination is when someone does not intend to procrastinate but they do so due to their inability to make quick and effective decisions or when they are under pressure of the upcoming task (Choi \& Chu, 2005).

Chu and Choi's study found dichotomous nature of procrastination; whereby taking into consideration the active as well as passive aspects of procrastination, and their subsequent effects on "purposive use of time, control of time, selfefficacy belief, coping styles, and outcomes including academic performance."

There are three interrelated components to psychological well-being: life satisfaction, unpleasant affect, and pleasant affect. Life satisfaction means a mental sense of satisfaction with life itself and affect refers to pleasant or unpleasant moods and feelings (Ryff, 1989).

High psychological wellbeing has proven to predict active procrastination, whereas low psychological well-being has proven to predict passive procrastination. These findings paved way for a richer discussion in psychology which not only acknowledged the nuanced nature of procrastination, but also challenged the negative connotations associated with procrastinating behavior.

The present study attempts to look at procrastinating behaviors and its link to psychological well-being amongst university undergraduate students of Institute of Business Administration in Karachi. A sheer number and diversity of students of the metropolitan city Karachi attend this business university, hence it has been chosen to acquire a dynamic sample. The study hypothesizes that active procrastination will result in high psychological well-being whereas passive procrastination will result in low psychological well-being. This study also aims to look at the gender differences in the nature of procrastination in relation to whether male or female university students indulge in active or passive procrastination behavior, and aims to study the affective state and psychological well-being following procrastination. 


\section{Literature Review}

Psychological well-being is a growing area of research, and the precise definition of well-being is yet to be resolved (Dodge, Daly, Huyton, \& Sanders, 2012). Despite the fact that significant researches have been conducted in pursuit to determine the definition of well-being, what constitutes of it, and the objective instruments to measure it, most of the previous research has been driven by description and dimensions of well-being, rather than its definition (Dodge et al., 2012).

More recent research has placed different emphases on what wellbeing is: ability to fulfil goals and life satisfaction (Pollard \& Lee, 2003, Foresight Mental Capital and Wellbeing Project, 2008). Stable wellbeing is when individuals possess the psychological, social and physical means to overcome related challenge. When individuals have more challenges than resources, their wellbeing reduces, and vice-versa. Depending on the kind of context, the definition of psychological well-being changes. (Dodge et al., 2012). In order to figure out how psychological well-being of a person, Carol Ryff created a scale to measure it. Ryff cover different aspects of well-being in her model, i.e. "autonomy, selfacceptance, personal growth, purpose in life, positive relations with others and environmental mastery." It is calculated by people subjectively evaluating their lives (Ryff, 1989).

In the recent years, procrastination amongst students has increased quite rapidly. It is something which has always been seen through a negative lens. It has always been considered as an abnormal behavior. However, a study by Chu and Choi (2005) revealed a new dimension of procrastination: active procrastination. This study defines active procrastinators as, "positive type of procrastinator." They choose to work under pressure, and they make deliberate decisions to procrastinate" (Choi \& Chu, 2005). The study showed that the amount of procrastination is the same for both, active and passive procrastinators, however active procrastinators are similar to non-procrastinators in terms of selfefficacy, academic performance, and time management.

A recent study by Morgan and Choi (2009) further researched the study done by Choi and Chu on active procrastination. The authors, Morgan and Choi, believed that the previous research can be expanded to include time management which will help researchers look at active procrastination through a broader lens, with multiple dimensions. In order for that to be possible, the authors developed a new measure of active procrastination which was more reliable and included multiple dimensions (Morgan \& Choi, 2009). This new measure, a 12-item scale, helped in further researches related to active procrastination.

Cao (2012) presented a similar study in which he compared procrastination of different grades' students. The result showed that the students who were younger, were active procrastinators, whereas students who were older, were passive procrastinators (Cao, 2012). Similarly another research by Rice, Richardson and Clark (2012) tried to test if there was a correlation between procrastination, psychological stress and perfectionism. What they found was that students who were active procrastinators, had lower levels of psychological stress than those who were passive procrastinators or even perfectionists (Rice, Richardson, \& Clark, 2012); therefore proving the hypotheses presented by Chu and Choi that active procrastination is positive procrastination (Choi \& Chu, 2005).

Another study observed the two different types of procrastinators, as well as non-procrastinators through selfregulated learning. The results were quite different from the previous studies. It showed that active procrastination was related to low motivation and negative behaviors. Active procrastinators had "low mastery-approach goal, high performance avoidance and work-avoidance goal, and low intrinsic motivation and task value" (Cao, 2012). Student who engaged in this form of procrastination were not as effective, chose to look for an easy way, and did not perform well on the tests compared to passive and non-procrastinators (Cao, 2012). This study critiqued and opposed the view presented by Choi and Chu that active procrastination produced positive results (Choi \& Chu, 2005).

An article by Pychyl stated that the researchers who use the word 'active' and the word 'procrastination' together are at fault. Active procrastination is an oxymoron, and this concept of active procrastination related to a semantic issue of language; one which they don't address specifically. This unexamined assumption about the meaning of words is a problem (Pychyl, 2009). Pychyl believes that procrastination is negative and it does not have any positive side to it. Delay can be positive or negative, and is a necessary part of our day to day lives. He says that we should not confuse active procrastination with passive procrastination. (Pychyl, 2009).

Passive procrastination refers to the stereotypical definition of procrastination; i.e. delaying tasks which are unpleasant, cumbersome, uninteresting or anxiety-provoking (Chu \& Choi, 2005). Passive procrastinators are more likely to possess an element of self-doubt. This suggests that as compared to active procrastinators, passive procrastinators are less likely to have high psychological well-being. Passive procrastinators have no intention to procrastinate; but they frequently end up doing so due to an inability to make quick, effective decisions. (Habelrih \& Hicks, 2015) Affectively, an 
approaching deadline ultimately causes passive procrastinators to feel pressured, thereby eliciting pessimistic thoughts regarding their capacity to achieve good results. (Habelrih \& Hicks, 2015) By not completing a task within a given deadline, the person may beleive that poor performance was influenced by lack of effort or greater pressure of impending deadline rather than a of lack of personal ability (Ferrari et al., 1995).

There is a dearth of research exploring the issue of gender differences in procrastination. Several researchers have found in terms of procrastination, the gender differences issue that can be considered from two different perspectives (Pychyl, Coplan, \& Reid, 2002). Firstly, gender can be studied through differences in the amount of procrastination by males and females; and secondly, gender differences in terms of the correlates of procrastination. Results from the majority of research in this topic have indicated no significant gender differences in procrastinating behavior of males and females (Effert \& Ferrari, 1989; Rothblum, Solomon, \& Murakami, 1986; Solomon \& Rothblum, 1984). However, some researchers (e.g. Haycock et al., 1998; Paludi \& Frankell-Hauser, 1986) have cautioned that there is evidence that women are much more predisposed to procrastinating as compared men. Moreover, women may in fact experience greater levels of procrastination-related anxiety than do men (Rothblum et al., 1986).

Though no significant difference has been found between boys \& girls on procrastination, suggesting that there is not much difference between boys and girls in terms of procrastination as a whole, but they do differ in fear of failure as a causal factor to procrastination. Regarding task aversiveness, results do not show any significant difference between boys and girls. Non-significant gender differences on task aversiveness nullify the effect of fear of failure in perpetuating higher procrastination in girls than boys.

Most recently, Ferrari, et al. (1999) examined the quality of relationships between women and men procrastinators with their mothers and fathers, as well as with their participants' more general social-support network. Ferrari et al. found that procrastination tendencies were significantly related to a person's increased risk of conflicts in their relationship with parents and best friend of the same sex, as well as less depth in the relationship with a person's father and same sex best friends. Based on this and the previous research reviewed, we can see that parental factors are positively correlated to procrastination and that there is some indication that parental attitudes are highly influenced by gender differences manifested in procrastination.

\section{Problem Statement}

The present study will be studying the relationship between psychological well-being and procrastination. The study will consider the effects of two types of procrastination - active and passive - on psychological well-being, and will also take into account gender differences in the aforementioned relationship.

\section{Rationale}

Just as in most parts of the world, procrastination is viewed as a negative behavior in Pakistan. There also exists a severe dearth of research on procrastination in Pakistan, and most of the studies that have been conducted have highlighted the negative consequences of this behavior. There is very little research done which studies the dual aspect of it in terms of the active and passive procrastination, and which highlights the positive point of view of it. The present study will highlight how procrastination can be useful to some and destructive for others. It also seeks to assist academic institutions, student counsellors and students themselves identify the nature and pattern of procrastinating behavior and cope with them accordingly.

\section{Hypotheses}

Hypothesis 1:

$\mathrm{H}_{1}$ : High psychological well-being will be positively correlated with active procrastination

$\mathrm{H}_{0}$ : High psychological well-being will not have any relationship with active procrastination

Hypothesis 2:

$\mathrm{H}_{1}$ : Low psychological well-being will be negatively correlated with passive procrastination.

$\mathrm{H}_{0}$ : Low psychological well-being will not have any relationship with passive procrastination.

Hypothesis 3:

$\mathrm{H}_{1}$ : Active procrastination will be higher in males as compared to females

$\mathrm{H}_{0}$ : There will be no difference between males and females in the active procrastination score

Hypothesis 4: 
$\mathrm{H}_{1}$ : Passive procrastination will be higher in females as compared to males

$\mathrm{H}_{0}$ : There will be no difference between males and females in the passive procrastination score

Since this is study is based on correlation, there will be no independent or dependent variables. Control variables will be education level and age.

\section{Methodology}

\subsection{Participants}

The random sample consisted of a total of 120 students collected using convince sampling of the students studying at the Institute of Business Administration (IBA) Karachi by meeting them personally at different buildings and places of the institute. All students belongs various demographic, socioeconomic \& ethnic background. First 60 responses of males and 60 responses of females are taken into account for research purpose.

\subsection{Measures}

\subsubsection{Active Procrastination Scale (Morgan \& Choi, 2009)}

Active Procrastination Scale is a 12-item self-report scale introduced by Morgan and Choi. It looks at four different dimensions: intentional decision, outcome satisfaction, preference for pressure and ability to meet deadlines. Each of the 12 items are rated through a 7-point Likert scale. A higher score will mean a higher level of active procrastination (Morgan \& Choi, 2009).

\subsubsection{Passive Procrastination Scale (Choi \& Chu, 2005)}

Passive procrastination is measured through the Passive Procrastination Scale, made by Chu and Choi. It is an 6-item self-report scale. It measures the traditional form of procrastination, such as self-doubt and delay in a task. Each of the 6 items are rated through a 7-point Likert scale. A higher score on this scale would mean a higher level of passive procrastination (Choi \& Chu, 2005).

\subsubsection{Ryff's Scales of Psychological Well-Being life (Ryff, 1989)}

Scale of Psychology Well-Being was introduced by Ryff (1989), and has been used in many different researches. It is a 18-item self-report scale, which looks at autonomy, environmental mastery, personal growth, positive relations, purpose in life and self-acceptance. Each of the items are measured on a 6 point Likert scale. Reverse scoring items are also used in this scale. A high score in one dimension would mean that the person has control over that aspect of their life (Ryff, 1989).

\section{Results}

\subsection{Multiple Regression}

Multiple linear regression analysis was used to find out the influences of active and passive procrastination on psychological wellbeing. The two predictors account for $88 \%$ of the variance in psychological wellbeing, $F(2,117)=$ $5.679, p<0.05, R^{2}=.0 .88$.

The contribution made by the two predictors were, beta1 $=0.385 p<0.05$, and beta2 $=-0.224 p<0.05$ and $B$ (constant) $=58.302, p<0.05$. Most significant contribution is made by active procrastination .

The relationship between active procrastination and psychological wellbeing was investigated using Pearson correlation coefficient. The results showed that there is a small positive correlation between the two $(r=0.243, N=120$, $\mathrm{p}<0.05)$. This shows that as active procrastination increases, a small proportion of psychological wellbeing also increases.

Pearson correlation coefficient was also used to determine the relationship between passive procrastination and psychological wellbeing. The results showed that there is a small negative correlation between the two $(r=-0.023, N=120$, $p<0.05)$. This shows that as passive procrastination increases, a small proportion of psychological wellbeing decreases. 
Correlations

\begin{tabular}{|ll|c|c|c|}
\hline & & $\begin{array}{c}\text { Total_Psych_Wellbei } \\
\text { ng }\end{array}$ & $\begin{array}{c}\text { Total_Active_Procrastina } \\
\text { tion }\end{array}$ & $\begin{array}{c}\text { Total_Passive_Procrast } \\
\text { ination }\end{array}$ \\
\hline \multirow{4}{*}{ Pearson Correlation } & Total_Psych_Wellbeing & 1.000 & .243 & -.023 \\
& Total_Active_Procrastination & .243 & 1.000 & .641 \\
& Total_Passive_Procrastination & .023 & .641 & 1.000 \\
\multirow{5}{*}{ Sig. (1-tailed) } & Total_Psych_Wellbeing &. & .004 & .400 \\
& Total_Active_Procrastination & .004 & .000 \\
& Total_Passive_Procrastination & .400 & .000 & 120 \\
& Total_Psych_Wellbeing & 120 & 120 & 120 \\
& Total_Active_Procrastination & 120 & 120 & 120 \\
\hline
\end{tabular}

\begin{tabular}{|c|c|c|c|c|c|c|c|c|c|c|c|c|}
\hline & & & & & Coeffi & ients ${ }^{a}$ & & & & & & \\
\hline \multirow{2}{*}{ Model } & \multicolumn{2}{|c|}{$\begin{array}{c}\text { Unstandardized } \\
\text { Coefficients }\end{array}$} & \multirow{2}{*}{$\begin{array}{c}\begin{array}{c}\text { Standardized } \\
\text { Coefficients }\end{array} \\
\text { Beta }\end{array}$} & \multirow{2}{*}{$t$} & \multirow{2}{*}{ Sig. } & \multicolumn{2}{|c|}{$\begin{array}{c}95.0 \% \text { Confidence } \\
\text { Interval for B }\end{array}$} & \multicolumn{3}{|c|}{ Correlations } & \multicolumn{2}{|c|}{ Collinearity Statistics } \\
\hline & B & $\begin{array}{l}\text { Std. } \\
\text { Error }\end{array}$ & & & & $\begin{array}{l}\text { Lower } \\
\text { Bound }\end{array}$ & $\begin{array}{l}\text { Upper } \\
\text { Bound }\end{array}$ & $\begin{array}{l}\text { Zero- } \\
\text { order }\end{array}$ & Partial & Part & Tolerance & VIF \\
\hline (Constant) & 58.302 & 4.497 & & 12.965 & .000 & 49.396 & 67.208 & & & & & \\
\hline $\begin{array}{l}\text { Total_Active_Procra } \\
1 \text { stination }\end{array}$ & .392 & .117 & .386 & 3.360 & .001 & .161 & .623 & 243 & 297 & .297 & .589 & 1.697 \\
\hline $\begin{array}{l}\text { Total_Passive_Proc } \\
\text { rastination }\end{array}$ & -.340 & .174 & -.224 & -1.951 & .053 & -.685 & .005 & .023 & -.177 & -.172 & .589 & 1.697 \\
\hline
\end{tabular}

\subsection{Independent T-Test}

An independent t-test analysis was conducted to measure whether there is a gender difference in the psychological wellbeing and procrastinating patterns.

For Total Active Procrastination, the Levene's test of significance for equality of variances was 0.212 . There was no significant difference in the scores of males $(M=50.25, S D=10.108)$ and females $(M=46.3, S D=8.62 ; t(120)=0.212$, $p=0.23$ ). Since the $p>0.05$, the result is not significant and the magnitude of the differences in the means was very small (eta squared $=0.00038$ )

For Total Passive Procrastination, the Leven's test of significance for equality of variances was 0.16 . There was no significant difference in the scores of males $(M=26.166, S D=6.16)$ and females $(M=25.7333, S D=6.67 ; t(120)=0.369$, $p=0.712$ ). Since the $p>0.05$, the result is not significant and the magnitude of the differences in the means was very small (eta squared $=0.0011$ )

For Total Psychological Wellbeing, the Leven's test of significance for equality of variances was 0.452 . There was no significant difference in the scores of males $(M=70.73, S D=8.086)$ and females $(M=66.05, S D=10.638 ; t(120)=2.715$, $p=0.08$ ). Since the $p<0.05$, the result is not significant and the magnitude of the differences in the means was very small (eta squared $=0.0585$ )

\section{Discussion}

The present study presented four hypotheses. The first hypothesis proposed that high psychological well-being will be positively correlated with active procrastination. A multiple regression analysis proved this hypothesis $(r=0.243, N=120$, $p<0.05)$. This shows that as active procrastination increases, a small proportion of psychological wellbeing also increases. This result was consistent with the results of a similar study conducted by Choi and Chu (2005) However, the size of the correlation was found to be small in the present study, indicating that there can be other factors apart from active procrastination that can contribute to the overall psychological well-being of an individual.

The second hypothesis proposed that high psychological well-being will be negatively correlated with passive procrastination. A multiple regression analysis proved this hypothesis $(r=-0.023, N=120, p<0.05)$. There was a small, but negative correlation between psychological wellbeing and passive procrastination. This shows that as active procrastination increases, psychological wellbeing decreases. This result was consistent with the findings of the study conducted by Choi and Chu (2005).

The present study included a nuanced dimension of testing gender differences in connection to procrastinating pattern and psychological wellbeing. The third and fourth hypotheses presented in this study were in connection to 
gender differences. The present study hypothesized that active procrastination will be higher in males as compared to females; however, the results revealed that there was no significant difference in the active procrastination between males and females $(M=46.3, S D=8.62 ; t(120)=0.212, p=0.23)$. The present study also hypothesized that passive procrastination will be higher in females as compared to males; however the results revealed that there was no significant difference between males and females in in terms of passive procrastination $(M=25.7333, S D=6.67 ; t(120)=0.369$, $p=0.712$ ), and both the genders were equally inclined towards being passive procrastinators.

The study also tested whether there is a difference in the amount of psychological wellbeing experienced by both males and females. It was found that there is no significant difference between the psychological wellbeing of males and females in the sample used for the purpose of the present study.

\section{Managerial Implications}

This present research shows that there is a relationship between active and passive procrastination and psychological well-being. Very few researches have been done on active and passive procrastination in relation to psychological wellbeing and therefore this research provides the readers a different aspect altogether. Both types of procrastination are different and have different effects, and through this research people will realize which procrastination they are engaging in and which is better for them. The results prove that procrastination is not necessarily dysfunctional and non-productive, it can be viewed in some circumstances as a way of prioritizing tasks. This is especially relevant for students since they can increase their productivity by participating in active procrastination rather than passive procrastination.

In the questionnaire, participants who viewed procrastination as a maladaptive behavior, were asked for solutions to get rid of procrastination. Some of the recommendations on how to control or minimize procrastination were, lectures on time management, encouragement from the teachers, peers, and/or family, lecture on procrastination, visit to a psychologist, discussions in social gatherings, turning off the internet or other gadgets which distract a person from their work. One of the solutions recommended by a participant was that the tasks should be made interesting enough that the students do not delay it and would want to do it as soon as possible. And some believed that the only thing which could work is self-motivation and self-efficacy.

\section{Limitations and Recommendation for Future Research}

One of the limitations of this study was in relation to the sample. The sample only comprised of undergraduate students within the age group of 18-24, and they all belonged to one business school in Karachi. Hence, the results obtained from this study cannot be generalized to a wider population to explain their procrastinating behavior. Future research must incorporate a more representative sample. For this purpose, a cross sectional research can be conducted on undergraduate students and middle aged adults to see whether the patterns of active and passive procrastination are same across different age group or varies with age.

Another limitation of this study is that it assumed that procrastination can only be explored in terms of two binaries - active and passive procrastination. However, there is a possibility that active and passive procrastination may occur along a wide spectrum, and a person may have characteristic traits of both active and passive procrastination. Future research should incorporate the possibility of procrastination occurring across a wide spectrum.

Future researchers may opt to conduct a longitudinal design to establish patterns of causal relationships between psychological well-being and different forms of procrastination. Furthermore, additional variables, such as impact of family interaction, peer and teacher encouragement can also be investigated in relation to patterns of procrastination and their effect on psychological wellbeing.

\section{Conclusion}

This study was used to determine the correlation between psychological well-being and active procrastination, and psychological well-being and passive procrastination. Through the research, it was proven that psychological well-being and active procrastination are positively correlated and psychological well-being and passive procrastination is negatively correlated. Even though procrastination is looked at as a dysfunctional behavior by $49.6 \%$ of our sample, it was proven that procrastination does not always lead to poor psychological well-being.

There might also be different factors, aside from procrastination, which could lead to poor psychological well-being, such as family pressure, personal problems and financial problems.

Out of 120 participants in our sample, 102 participants (86.4\%) said that they procrastinate by surfing the internet. When they were asked whether they want to get rid of procrastination, and what recommendations they give to control 
procrastination, $72.6 \%$ of the sample said they wanted to get rid of it and majority of the sample said that procrastination can be controlled through encouragement from teachers and peers.

\section{References}

Brownlow, S., \& Reasinger, R. D. (2000). Putting off Until Tomorrow What is Better Done Today: Academic Procrastination as a Function of Motivation Towards College Work. In T. A.

Cao, L. (2012). Differences in procrastination and motivation between undergraduate and graduate students. Journal of the Scholarship of Teaching and Learning, 39-64.

Cao, L. (2012). Examining 'active' procrastination from a self-regulated learning perspective. Journal of Educational Psychology.

Choi, J., \& Chu, A. (2005). Rethinking procrastination: Positive effects of "active"

Procrastination behavior on attitudes and performance. Journal of Social Psychology, 145, 245-264.

Dodge, R., Daly, A., Huyton, J., \& Sanders, L. (2012). The challenge of defining wellbeing. International Journal of Wellbeing, 222-235.

Effert, B. R., \& Ferrari, J. R. (1989). Decisional procrastination: Examining personality correlates. Journal of Social Behavior and Personality, 4, 151-156.

Ellis, A. \& Knaus, W. (1977). Overcoming procrastination. New York: Institute for Rational Living.

Fee, R. L., \& Tangney, J. P. (2000). Procrastination: A means of avoiding shame or guilt? Journal of Social Behavior and Personality, 15, 167-184.

Ferrari, J.R., Johnson, J.J., \& McCown, W.C. (1995). Procrastination and task avoidance: Theory, research, and treatment. New York: Plenum.

Ferrari, J. R., Harriott, J., \& Zimmerman, M. (1999). The social support networks of procrastinators: Friends or family in times of trouble? Personality and Individual Diff erence, 26, 321-334.

Foresight Mental Capital and Wellbeing Project (2008). Final Project report. The Government Office for Science, London

Goode, C. (2008). Effects Of Academic Procrastination: Students Procrastination Affects More Than Grades. Retrieved from website http://homeworktree.com/media/news- releases/academic-procrastination accessed on October 20, 2015

Habelrih, E. A., \& Hicks, R. E. (2015). Psychological Well-Being and Its Relationships with Active and Passive Procrastination. International Journal of Psychological Studies.

Harris, N.N., and Sutton, R.I. (1983), "Task Procrastination in Organizations: A Framework for Research," Human Relations, 11, 987-996.

Haycock, L. A., McCarthy, P., \& Skay, L. C. (1998). Procrastination in college students: The role of self-efficacy and anxiety. Journal of Counseling \& Development, 317-324.

Hussain, I. \& Sultan, S., (2010). Analysis of procrastination among university students. Procedia Social and Behavioral Sciences, 5, 18971904.

Joseph R. Ferrari (Ed.), Procrastination: Current Issues and New Directions. 15-30. Select Press.

Lay, C.H. (1986). At Last, My Research Article on Procrastination. Journal of Research inPersonality, 20, 474-495.

Morgan, S. V., \& Choi, J. (2009). Why Not Procrastinate? Development and Validation of a New Active Procrastination Scale. The Journal of Social Psychology, 195-211.

Owens,A. \& Newbegin, I. (1997). Procrastination In High School Achievement: A Causal Structural Model. Journal Of Social Behaviour And Personality, 3, 201-214. Psychology Today: https://www.psychologytoday.com/blog/dont-delay/200907/activeprocrastination thoughts-oxymorons

Paludi, M. A., \& Frankell-Hauser, J. (1986). An idiographic approach to the study of women's achievement striving. Psychology of Women Quarterly, 10, 89-100.

Pollard, E., \& Lee, P. (2003). Child well-being: a systematic review of the literature, Social Indicators Research, 61(1), 9-78.

Pychyl, T. A. (2009). Active Procrastination: Thoughts on Oxymorons. Retrieved from

Pychyl, T. A., Coplan, R. J., \& Reid, P. A. (2002). Parenting and procrastination: Gender Differences in the Relations between Procrastination, Parenting Style and Self-Worth in Early Adolescent. Journal of Personality and Individual Differences, 271-285.sch

Rice, K., Richardson, C., \& Clark, D. (2012). Perfectionism, procrastination, and psychological distress. Journal of Counseling Psychology, 288-302.

Rothblum, E. D., Solomon, L. J., \& Murakami, J. (1986). Affective, cognitive, and behavioral differences between high and low procrastinators. Journal of Counseling Psychology, 33(4), 387-394.

Ryff, C. D. (1989). Happiness is everything, or is it? Explorations on the meaning of psychological well-being. Journal of Personality and Social Psychology, 1069-1081.

Saleem, M., \& Rafique, R. (2012). Procrastination and Self-Esteem among University Students. Pakistan Journal of Social and Clinical Psychology, 50-53.

Solomon, L. J., \& Rothblum, E. D. (1984). Academic procrastination: frequency and cognitive behavioral correlates. Journal of Counseling Psychology, 31, 503-509.

Yaakub, N.F. (2000). Procrastination among Students in Institutes of Higher Learning: Challenges for K-economy: Malaysia. University Of Utara retrieved from website http://www.postpone/Mahdzan.com accessed on October 13, 2015

Zarick, L. M., \& Stonebraker, R. (2011). I'll do it Tomorrow: The Logic of Procrastination. College Teaching, 211-215. 